\title{
Trends of Administrative and Academic Leadership towards Achieving Governance, An Applied study in Official Jordanian Universities in Southern Jordan
}

\author{
Ghazy A. Al-Badayneh ${ }^{1}$ \\ ${ }^{1}$ Faculty of Business, Business Administration Department, Tafila Technical University, At-Tafila, Jordan \\ Correspondence: Ghazy A. Badayneh, Faculty of Business, Tafila Technical University, At-Tafila, P.O.Box179, \\ Tafila, 66110, Jordan.
}

Received: March 9, 2021

Accepted: March 29, 2021

Online Published: April 2, 2021

doi:10.5539/ibr.v14n5p1

URL: https://doi.org/10.5539/ibr.v14n5p1

\begin{abstract}
This study aimed at analyzing the trends of administrative and academic leaders towards achieving governance in the official Jordanian universities in southern Jordan. To achieve the objectives of the study, a questionnaire was developed covering the study variables, it was distributed to the study population consisting of administrative and academic leaders in three official universities in southern Jordan, which is Mutah, Al-Hussein Bin Talal, and Tafila Technical), who were (904) employees, the study sample was selected in a random, stratified proportional method of (452) respondents forming (50\%) of the study population. Descriptive and analytical statistical methods were used, using the statistical package (SPSS.16), the study reached a set of results including the following: That the Mean of the respondents 'perceptions of the dimensions of the administrative and academic leadership trends in public universities in southern Jordan had a high degree, and that the Mean of the respondents' perceptions of the governance dimensions in public universities in southern Jordan had a high degree. The study results showed a statistically significant positive relationship between the independent variable (leadership trends) and its various dimensions and the dependent variable (governance) and its various dimensions. The study revealed many recommendations, including: Paying attention to continuous training of leaders on understanding administrative activity, especially in the field of leadership behavior in universities to activate the role of leaders in these universities, spreading and strengthening governance culture among their employees as it will be reflected in the decisions of the institution, in turn on its performance.
\end{abstract}

Keywords: governance, leadership trends, public universities in southern Jordan

\section{Introduction}

In the current era the world as a whole, and the Arab region and Jordan in particular are witnessing many developments and transformations, many challenges and changes in all walks of life and in all its sectors, as our era is characterized by modernity and speed and the emergence of many concepts, including globalization, competition, digital revolution, electronic commerce, financial and economic crises, and the spreading of internet to reach every home. The higher education sector in Jordan is not far from all these developments and transformations, thus the Jordanian higher education institutions face a great challenge that is difficult to overcome through traditional methods, which made it necessary for these institutions to track the impact of international universities that dealt with these challenges using modern methods and approaches that will push these institutions up to rank among the best international universities. Whereas, the comprehensive quality management and in particular the quality assurance standards, whether global or local, is a modern management approach that improves and develops the quality of higher education, thus opens up to the world and enters the competitive market, and interacts with these universities. Where governance standard as one of the quality assurance standards for the administrative sciences program issued by the Jordanian Higher Education Accreditation Commission is set by a group of experts and specialists in the field of quality control, and based on international standards (the Quality Assurance Standards Manual for the Administrative Sciences Program) and given the importance of this standard along with the rest of the standards in order to obtain the Quality Assurance Certificate issued by the Accreditation Commission for Jordanian Higher Education Institutions, the researcher found that it is necessary to identify the trends of administrative and academic leaders in Jordanian public universities In the southern region towards the application of this standard. 


\subsection{The Study Problem}

The main problem in this research is to identify the trends of administrative and academic leaders towards achieving governance in Jordanian higher education institutions, as the official Jordanian universities in southern Jordan were chosen, to identify the extent of the administrative and academic leaders 'trends towards achieving governance, by trying to answer the question: What is the impact of the administrative and academic leadership trends towards achieving governance in the official Jordanian universities in southern Jordan?

\subsection{Objectives of the Study}

This study aims at:

- Enriching the Arab library with specialized knowledge related to the study variables.

- Studying the respondents' perceptions of the administrative and academic leadership trends, and each of its dimensions (objectivity, effectiveness, flexibility) in the official Jordanian universities in southern Jordan.

- Learn about the respondents' perceptions towards achieving governance, and each of its dimensions (justice, equality, reliability) in the official Jordanian universities in southern Jordan.

- Presenting practical recommendations, for studied community.

\subsection{The Importance of Study}

The importance of the study is determined in two basic aspects: the theoretical importance and the scientific importance:

Theoretical importance, which is illustrated by:

This study is of interest to researchers in the trends of administrative and academic leaderships, it also contributes to adding a study on the literature of the current topic and providing the library with new research for researchers and those interested in the trends of administrative and academic leaders towards achieving governance, an applied study in the official Jordanian universities in southern Jordan.

Scientific importance, which is demonstrated by:

The results of this study are important for the official Jordanian universities in southern Jordan; moreover, this study is important for interested decision-makers, the trends of administrative and academic leadership towards achieving governance.

\subsection{Study Questions}

and academic leadership in their dimensions (objectivity, administrative communication, and effectiveness) on achieving governance in its dimensions (justice, equality, accountability) in the official Jordanian universities in southern Jordan.

From this hypothesis these sub-hypotheses are branched:

- What is the level of the impact of administrative and academic leadership trends (objectivity, effectiveness, flexibility) in the official Jordanian universities in southern Jordan?

- What is the level of achieving governance (fairness, equality, reliability) in the official Jordanian universities in southern Jordan?

\subsection{Study Hypotheses}

The study attempts to test the validity of this main hypothesis: There is no statistically significant impact at the level of significance $(\alpha \leq 0.05)$, the attitudes of administrative

- The first sub-hypothesis: There is no statistically significant impact at the level of significance $(\alpha \leq 0.05)$ for administrative and academic leadership trends in their dimensions (objective, administrative communication, effectiveness) on justice and equality as one of the dimensions of achieving governance in the official Jordanian universities in southern Jordan.

- The second sub-hypothesis: There is no statistically significant impact at the level of significance $(\alpha \leq 0.05)$ for administrative and academic leadership trends in their dimensions (objective, administrative communication, effectiveness) on the accountability dimension as one of the dimensions of achieving governance in the official Jordanian universities in southern Jordan. 


\subsection{The Limits of the Study}

- The objective limit: the study was limited to knowing the trends of the administrative and academic leaders towards achieving governance, an applied study in the official Jordanian universities in southern Jordan.

- The human limit: This study was limited to a sample of administrative and academic leaderships in official Jordanian universities in southern Jordan.

- The spatial limit: this study was applied at the University of Mu'tah, and the University of Hussein bin Talal, and Tafila Technical University.

- Time limit: This study was applied in the academic year 2019/2020.

\section{Literature Review}

\subsection{Leadership}

\subsubsection{Concept Leadership}

Leadership one of the basic pillars of the administrative process within organizations of all types and activities because it has a direct impact on individuals and businesses within organizations, Leadership is considered an essential process in motivating individuals and raising their morale, which is reflected on their performance and happiness at work, their job satisfaction and thus affects the achievement of organizational goals efficiently and effectively (Ayasrah, 2008).

Hill (2016) defined leadership more precisely, defining it as "the ability to fully or partially clarify goals, motivate subordinates, and push them to achieve these goals, moreover, it is the ability to predict and maintain flexibility, and to enable subordinates to make positive changes whenever required.

Magee (2018) argues that leadership involves any work that others are required to do and accomplish, it is a style practiced by a leader with the goal of achieving the clear goals of the organization.

Al-Ajami, (2008) added that leadership works to improve communication and link between workers themselves and between workers and higher management in the organization and provide them with the care, training and qualification in addition to their support in solving problems that they may face during their work, leadership is a guiding process that directs and guides individuals to achieve specific goals and influence their ideas and convictions to gain their confidence, raise their morale, and motivate them towards achievement to achieve the desired goals of the organization in an effective and efficient manner.

Schnurr and Schroeder, (2019) added that the concept of leadership has a great attention of people for a long time, caring about a new leader which is welcome, to have a new perspective in how to inspire others, to institute change and enhance creative solutions of problems, Researchers and management theoreticians have recently demonstrated a growing interest in the issues associated with leadership and the factors that determine its effectiveness

\subsubsection{Importance of Leadership}

Moreover, leadership plays an important role in the organization, its importance lies in being a link between workers and the organization's plans and perceptions, as the organization seeks through the application of different leadership styles to facilitate the processes within it and reduce organizational conflicts and solve them appropriately to serve the productive process and the routine and strategic processes within the organization, the leadership works to prepare the organization and qualify the individuals to keep pace with the internal and external changes surrounding the organization (Magee,2018).

The role of the leader in the organization is not limited to issuing orders and ensuring that they are implemented, but goes beyond that to working in a team spirit and maintaining an environment of happiness and satisfaction among the workers of the organization, which works to activate performance and stimulate the administrative and productive process within the organization, as well as to form relationships between employees and management. The participation of workers in the various administrative decisions and their participation in developing plans and how to implement them (Kanaan, 2009).

To achieve the desired objectives of the leadership, there are a number of modern leadership forms and methods that play an important role in enhancing the organization's ability to deal with individuals within it, it also works to develop the capabilities of workers and make optimal use of them, and achieve a number of benefits that accrue to workers such as providing a suitable work environment and creating an environment of familiarity and happiness for them. In addition to benefits that accrue to the organization such as achieving its various organizational goals and strategies (Maher, 2014). 
Leadership Lens: It adopts its name from MacIntyre's in 2004, Aristotelian perspective of Telos as an ultimate end to achieve which is good of humankind. However, TLL is introduced as a theoretical lens provides enrichment within existing and future theory and practice of leadership when applied. Conceptualized as comprehensive theoretical framework and main guidance to interested scholars and practitioners, it adopts of three principles (By, R. T. 2021):

-First, the lens perceives leadership as a responsibility of many, not excluded for the few by focuses on doing rather than being. Barker translated this lens by the notion that leadership creates the leader, not the contrary side.

-Second, leadership is the shared pursuit of worthy purpose and outcome that exceeds individual and individual organization, and in return should declare core values of organizations and sustain fitness with cultural dimensions and operating behaviors.

-Third, leadership purpose is determined by the sustainable development which is communicated to others through vision and missions, and the high advocate and commitment to sustain performance management, in the form of performance standards, action plans, furthermore the combination of qualitative and quantitative indicators of performance as balanced score card to keep alignment with sustainability in development at the final point.

\subsection{Governance}

\subsubsection{Governance Concept}

The term "Al-Hawk amah" in Arabic language is the abbreviated translation of the term governance, while the scientific translation of this term, which was agreed upon, is "The method of exercising the powers of good administration".

The term governance means "the source or reference upon which the governance of the organization is based. It is a set of laws, regulations and decisions aimed at achieving quality and excellence in performance by choosing appropriate and effective methods to achieve the plans and objectives of the company or institution" (Kafi, 2013).

Governance is also defined as "the ability to monitor and control all administrative processes in a scientific and rational manner" (AL-Arini, 2014).

Williamson (1999) believes that corporate governance is a strategy that the organization adopts in its endeavor to achieve its main goals, within an ethical perspective that stems from within it as an independent and self-standing moral personality, and that it has an administrative structure and internal regulations and bylaws that ensure that it achieves these goals with its own capabilities, free from the authority pressure of any individual within it to the extent that it does not conflict with the interests of other relevant groups.

\subsubsection{Characteristics of Governance}

The characteristics of governance can be derived from its definition as follow: (Nouri \& Salman, 2010)

- Enhancing and activating the performance of institutions and maximizing the market value.

- Accounting accountability for the management of various institutions.

- Full emphasis on the interaction between the external systems of the business of institutions.

- Achieving balance in contractual relations between the departments of institutions and other parties.

- Working to reach the best exercise of power for any institution.

- Working to provide adequate guarantees to curb administrative and financial corruption.

- Change the traditional internal role and make a shift in its activities from merely emphasizing protection, accuracy, efficiency, and commitment to active participation in predicting the behavior of the operational performance of any institution

\subsubsection{Governance Determinants}

In order to benefit from the advantages of implementing governance, a set of basic determinants and factors that ensure the proper application of the principles of governance must be present, but in reality, they represent controls to ensure the effective implementation of governance, they are divided into two parts: external determinants and internal determinants (Adelopo, 2010) as follows:

- External determinants: These determinants are represented in the environment or climate in which you deal 
with organizations, which may differ from one country to another, they include:

1- Laws, regulations and legislation governing capital markets.

2- Existence of good financial legislations that guarantee the provision of the necessary funding that encourages organizations to expand and compete internationally.

3- The competence of regulatory bodies and agencies to ensure the integrity and accuracy of data and information that are published, and take the necessary measures to ensure that these bodies and supervisory bodies exercise the powers entrusted to them.

4- The role of civil society institutions in ensuring the commitment of its members to the behavioral, professional and ethical aspects, which are represented in the associations of accountants and auditors.

-Internal determinants: It includes different rules and methods. The organizations that are interested in establishing sound administrative structures including how to make decisions within organizations and the distribution of powers and duties among the parties concerned with the application of the concept of governance, such as, shareholders, board of directors and other types of stakeholders to ensure that there is no conflict of interest between all parties, to achieve the interests of investors in the long term (Christensen \& peter, 2007).

\subsubsection{Goals and Importance of Governance}

Governance is of great importance in universities because it provides the organizational structure through which universities 'goals can be achieved, the means for achieving those goals and performance monitoring, its importance in universities management can be determined as follows (AL-Arini, 2014).

- Contribute to creating independent institutions with boards and governing bodies that carry out the responsibility of strategic direction and enhance management effectiveness in their institutions

- Helping universities achieve their outcomes and goals in the desired possible methods, and with the lowest costs.

- Detecting weaknesses and deficiencies in performance and weak outputs.

- Ensuring balance and commitment to both operational short-term concerns versus strategic long- term orientation.

- Enhancing competitiveness and reducing cases of corruption in managerial and financial domains

- Optimizing the university's resources and ensuring the rights and interests of the university's workers from the two bodies: the administrative and the teaching staff, without discrimination and favoritism.

-Governance is considered a kind of self-monitoring and cybernetic, which leads to the fairness and safety in legal application of legislation, which insures thus quality of management and the prevail age of workers' rights, thus achieving community satisfaction with universities and their performance.

The importance of good governance is highlighted by setting detailed, measurable standards and working mechanisms for performance indicators of the degree of is implementing governance in universities in terms of choosing the university president, the council of deans, groups, and departments. This is done by developing realistic visions, means, and goals in real partnership with the university administration and stakeholders so that everyone bears the responsibility to facilitate its achievement.

Numerous literature has stated that corporate governance is communicated by set of core pillars for the purpose of achieving its goals:(responsibility, accountability ,transparency and disclosure, , justice, independence, laws, and regulations) (Al-Abdali, 2012).

\subsection{Previous Studies}

Al-Saadi Study (2021) "The Impact of Creative Leadership on the Organization's Effectiveness: Strategic Thinking as a Mediator Variable a Case Study - Dubai Police" The study aimed at identifying in general the impact of creative leadership on the organizational effectiveness: with the presence of strategic thinking, and knowledge of the respondents 'perceptions of the level of application of each of: Creative leadership And strategic thinking as a mediator variable, and the organization's effectiveness in Dubai Police, The study used the analytical descriptive approach to measure the variables of study, as it relied on statistical methods such as descriptive statistics, standard deviation, as well as simple regression, and multiple linear regression, The study population was represented in the employees of all the supervisory leadership in the Dubai Police, totally reached (1069) individuals, the study used the simple stratified sample method, where the study sample amounted to (357) individuals. The questionnaires were distributed to them as they were all retrieved, (58) 
were excluded, due to invalid for statistical analysis, thus the questionnaires valid for statistical analysis were (299) questionnaires, the results of the study showed a statistically significant proportional relationship between the creative leadership and its dimensions, combined in strategic thinking. The study recommended the necessity of continuing to pay attention to Dubai Police workers and work to continue to motivate workers, which have an impact on developing loyalty and their job affiliation, and continue expanding workers sufficient authorities that are suited their qualifications and experiences they have.

Al-Khathami study, (2020), Creative leadership among school leaders in Khamis Mushait governorate from the teachers 'point of view (field study). The study aimed at identifying the degree to which school leaders in Khamis Mushait governorate practice creative leadership the view point of teachers, the study relied on the descriptive and analytical approach. The study community represented the teachers working in the Khamis Mushayt governorate, and the study sample reached (356) teachers, to whom the study questionnaire was distributed. The study used multiple statistical methods such as Cronbach Alpha, Pearson Correlation Coefficient, Descriptive Statistics, Arithmetic Mean, Standard Deviations, Single Analysis Test, and T-Test.

Al-Hrout study (2018) "Trends towards the application of e-governance in Jordanian private universities and its impact on university performance excellence: a field study." This research aimed at revealing the impact of applying e-governance in Jordanian private universities on university performance excellence, the study was applied to seven private universities in the city of Amman, the student community is composed of teaching and administrative staff of the researched universities, which amount to (2864), the study sample was chosen by the stratified randomized method, (385) questionnaires were distributed among the members of the teaching and administrative staff, (341) questionnaires were retrieved and (12) questionnaires were excluded due to invalid for analysis. In order to answer the questions of study and test its hypotheses, the researcher used a number of inferential, descriptive statistical methods, using the programs of the Statistical Package for Social Sciences (SPSS). ). The study stated many results and recommendations, the most important of which are: The level of trends towards implementing e-governance in universities was high, and the study found a statistically significant impact of all e-governance trends on university performance excellence.

Moufiedah,German study (2018), titled Administrative Leadership and its Role in Supporting Administrative Creativity, a Case Study of the Central Library, Al-Arabi Bin Mahidi University - Umm Al-Bouaghi - The study aimed at knowing the administrative leadership and its role in supporting administrative creativity in the Central Library of the University of Al-Arabi, and the descriptive and analytical approach was used in this study, using a questionnaire tool to collect data, distributed to the sample of the study (41) questionnaires were analyzed from the original sample size using the Statistical Package for Social Sciences (SPSS) program.

Al-Rashidi, Ali Dabyan (2018) study entitled "Transformational Leadership and its Relationship to Organizational Creativity among Deans and Heads of Departments at Governmental and Private Universities in Riyadh". The research aims to determine the level of application of transformational leadership and its impact on organizational creativity in Saudi and private universities, by design a questionnaire that included (55 items, a field research was conducted on all group deans and department heads in eight Saudi public and private universities in Riyadh, and the number of sample individuals reached (237). The researcher recovered (147) responses, (62\%) of the responses data were completed. Among the most important findings of the research is that all dimensions of transformational leadership are practiced at a high level and that the practice of organizational creativity in all its dimensions is at a medium level. It was also evident that there are statistically significant differences in the responses of the research sample towards the practice of attracting, retaining creators, and practicing creativity attributable to gender, university ownership, specialization, and experience in university work and the existence of a statistically significant effective impact at the level of (0.05) or less between the practice of transformational leadership and the development of academic leaders' practice of organizational creativity. The research also reached the most important recommendations represented in the necessity of reconsidering the criteria according to which university leaders are selected from department heads and group deans. To become more in line with the requirements of contemporary changes, and the availability of an organizational climate that supports transformational leadership in Saudi universities in attracting and retaining innovators and to analyze the responses of the study sample individuals to find the relationship between administrative leadership and administrative creativity.

Al-Jabali \& Al-Mahamid, (2018) study entitled "The Impact of University Governance on Employee Satisfaction and Retention: A Field Study in Jordanian Private Universities"

Study aimed to investigate the impact of the factors of governance of private universities on employee satisfaction and retention by identifying the most important factors affecting retention of workers in Jordanian 
private universities and identifying the direct impact of applying the principle of university governance to employee satisfaction as well as the direct impact on employee retention. The questionnaire was used as a tool to collect data. The study showed the existence of positive impact relationship with statistical significance for fairness and equity in job satisfaction for employees in Jordanian private universities, the existence of a positive impact relationship with statistical significance for fairness and equity in retaining workers in Jordanian private universities. The study concluded the following recommendations: the need to ensure justice and fairness for university workers, and the focus of the governance boards in universities on achieving the values of justice and fairness among workers in private universities to ensure their commitment and loyalty to the university.

Al-Senussi (2016) study entitled: "The Impact of Governance on Achieving Competitive Advantage (Field Study in Private Hospitals in Amman)." The study aimed to identify the effect of governance in achieving competitive advantage. A field study in private hospitals in Amman, a questionnaire was developed. The results showed the existence of a statistically significant impact of the application of governance by its combined dimensions on the competitive advantage by its combined dimensions and recommended the need to implement governance dimensions in private hospitals.

Nwachukwu, Hieu, (2020) study, entitled "Creative Leadership and Creativity: An Overview" The study aimed at finding the best ways to make leadership styles to be more creative to cope with rapid changing conditions both internal and external conditions within their environments ., the study methodology based on scientific research about this subject during the period of time extended between 1978-2020. Which reached to?

(66) Scientific research, accordingly, the study concluded the importance of the skills related to administrative creativity and the creation of an effective work environment to support the attainment of strategic objectives, high profits and investments for their organizations

Yuliastuti \& Tandio (2020) study. Leadership Style on Organizational Culture and Good Corporate Governance. The study aims to investigate the mediating effect of organizational culture variables between leadership style and Good Corporate Governance (GCG) in the Village Credit Institution (LPD) in Gianyar Regency. The study sample was 73 LPD of Gianyar Regency. The study used Partial Least Square (PLS) as an analysis technique. The results stated that organizational culture provides a partial mediation effect on the relationship between charismatic leadership styles and GCG, whereas organizational culture provides full mediation in the relationship between transformational leadership styles and GCG,. Which declare the importance of a good organizational culture in improvement GCG in the institution?

\section{Study Methodology}

The study adopted the methodology of descriptive and field-analytical research. On the level of descriptive research, a desk survey was conducted, the studies and theoretical and field researches were examined in order to formulate the foundations and premises on which the theoretical framework is based, and take into consideration the most important previous studies, which constitute a vital tributary to the study including the cognitive hubs that it contains. As for the analytical field research, a comprehensive exploratory survey was conducted, and all data gathered was analyzed by answering questionnaires, using appropriate statistical methods, the study was based on the questionnaire that was developed.

\subsection{Study Population}

The study population consisted of the academic and administrative leadership in the official Jordanian universities in southern Jordan, who were (904) distributed as follows, as shown in Table (1):

Table 1. Distribution of administrative academic leaderships in the official Jordanian universities in southern Jordan

\begin{tabular}{ll}
\hline University Name & Number of administrative leaderships \\
\hline Mutah University & 400 \\
\hline Al-Hussein Bin Talal University & 318 \\
\hline Tafila Technical University & 186 \\
\hline Total & 904 \\
\hline
\end{tabular}

Source: Prepared by the researcher based on the statistics of human resources departments in universities 2019 


\subsection{Study Sample}

The study sample was selected in a proportional stratified randomized method of (452) respondents, representing $(50 \%)$ of the study population. The questionnaire was distributed to all the members of the study population, who were randomly selected, (404) questionnaires were retrieved with a retrieval rate of (90\%), (19) questionnaires were excluded because of their lack of validity for statistical analysis, 385 questionnaires were subjected to the analysis, i.e. $85.2 \%$ of the questionnaires distributed to the study population, which is an acceptable percentage for the purposes of scientific research.

Table (2) below shows the number of questionnaires retrieved from each university and their percentage from the questionnaires distributed:

Table 2. The number of retrieved questionnaires and their percentage from the distributed questionnaires

\begin{tabular}{lccc}
\hline University Name & $\begin{array}{c}\text { Distributed } \\
\text { questionnaires }\end{array}$ & $\begin{array}{c}\text { Questionnaires } \\
\text { recovered }\end{array}$ & $\begin{array}{c}\text { The percentage of recovered } \\
\text { questionnaires }\end{array}$ \\
\hline Mu'ta university & 200 & 180 & $90 \%$ \\
\hline Al-Hussei Bin Talal & 159 & 135 & $85 \%$ \\
\hline Tafila technical & 93 & 89 & $96 \%$ \\
\hline Total & 452 & 404 & $90 \%$ \\
\hline
\end{tabular}

Source: Prepared by the researcher

The following table shows the distribution of the study sample according to their personal and functional variables

Table 3. Distribution of study sample individuals according to their personal and functional variables

\begin{tabular}{|c|c|c|c|}
\hline Variable & Variable classes & Number & percentage \\
\hline \multirow[t]{3}{*}{ Sex } & Males & 325 & 80.4 \\
\hline & Females & 79 & 19.6 \\
\hline & Total & 404 & 100.0 \\
\hline \multirow[t]{5}{*}{ Age } & Less than 30 & 65 & 16.0 \\
\hline & 30-39 years old & 105 & 25.7 \\
\hline & 40-50 years old & 170 & 42.5 \\
\hline & From 50 years and over & 64 & 15.8 \\
\hline & Total & 404 & 100.0 \\
\hline Educational & Bachelor of & 45 & 11.1 \\
\hline \multirow[t]{4}{*}{ qualification } & Higher Diploma & 101 & 25.0 \\
\hline & M.A. & 188 & 46.5 \\
\hline & $\mathrm{PhD}$ & 70 & 17.4 \\
\hline & Total & 404 & 100.0 \\
\hline \multirow[t]{5}{*}{ Career Level } & President / Vice President / Assistant Chancellor & 5 & 1.2 \\
\hline & Dean/Deputy/Assistant Dean of the College & 110 & 27.2 \\
\hline & Head of the Academic Department & 103 & 25.5 \\
\hline & Director / Assistant Director of Department / Unit & 186 & 46.1 \\
\hline & Total & 404 & 100.0 \\
\hline \multirow[t]{5}{*}{ Experience } & 5 years or less & 67 & 16.7 \\
\hline & From 5 to 9 years & 74 & 18.3 \\
\hline & From $10-14$ years old & 163 & 40.3 \\
\hline & 15 years and over & 100 & 24.7 \\
\hline & Total & 404 & 100.0 \\
\hline
\end{tabular}

\subsection{Study Tool}

A questionnaire was developed based on Likert's five-way scale (Likert) consisting of five options, ranging from completely agrees and never agrees with a relative weight (1-5). The questionnaire was divided into two groups, the first one is related to the personal data of the respondents, the second group is related to the core subject of the research which consists of a number of items that relate to three main axes of the independent variable, which are the administrative leadership trends in their dimensions (objectivity, administrative communication, and effectiveness). It will also include a number of items covering the dependent variable to achieve governance in its dimensions (fairness, equality, reliability). 


\subsubsection{Validity of the Tool}

The questionnaire was presented to a number of arbitrators from among the teaching staff in universities, to ensure the validity of the items of the questionnaire.

\subsubsection{Stability of the Tool}

The internal consistency coefficient for the study tool was extracted, depending on the Cronbach's Alpha coefficient for each of the study variables in all its dimensions, the values of the stability coefficient were high and indicated the reliability and consistency between the items of the tool.

Table 4. The coefficient of internal consistency for each of the study variables in all its dimensions

\begin{tabular}{|c|c|c|c|}
\hline Variable & The dimension & The items & Cronbach Alpha \\
\hline Independent variable & Objectivity & $1-5$ & 0.780 \\
\hline \multirow[t]{2}{*}{ (Management leadership trends) } & Administrative Communications & $6-10$ & 0.755 \\
\hline & Effectiveness & $11-19$ & 0.810 \\
\hline Dependent & Justice and equality & $20-24$ & 0.845 \\
\hline (governance) & Accountability & $25-30$ & 0.890 \\
\hline
\end{tabular}

The data in Table (4) show that the stability coefficients for the dimensions of the Management leadership trends variable ranged between $(0.755-0.810)$, with regard to governance, the stability coefficients ranged between (0.845 - 0.890), such values are considered acceptable for the purposes of the current study.

\subsection{Statistical Treatment}

To answer the study questions and test the validity of its hypotheses, descriptive and analytical statistics methods were used, using the statistical package (SPSS.16). The following is a presentation of the statistical methods that were used:

Descriptive Statistic Measures to describe the characteristics of the study sample, depending on the frequencies and percentages, the VIF test (Variance Inflation Factory) and Tolerance test were used to ensure that there is no high correlation (Multicollinearity) between the independent variables, and testing the skewness coefficient to ensure that the data follow a normal distribution. Multiple Regression Analysis was used to test the validity of the study models and the effect of the independent variable and its dimensions on the dependent variable and its dimensions, and the Stepwise Multiple Regression Analysis to test the entry of the independent variables into the prediction equation of the dependent variable.

\section{Presenting and Discussing Findings and Recommendations}

This chapter presents the results of the statistical analysis of the study dimensions and discusses the findings and recommendations that were drawn based on the results of the study. The results of the descriptive statistical analysis of the data were relied upon, which include arithmetic means, standard deviations for all dimensions of the independent and dependent study, and the component items for each dimension.

\subsection{Answer the First Question}

Identify the directions of the administrative and academic leadership trends, and each of its dimensions are dimensions, administrative communications, and official Jordanian universities in southern Jordan? To answer this question, calculate the arithmetic means and standard deviations, to correct the vocabulary of the sample, at the level of each dimension, and the total dimension of the administrative and academic rentals, and Table (5) shows the results of that: 
Table 5. The means and standard deviations of the perceptions of the of the individuals of the study sample towards the administrative and academic leadership trends.

\begin{tabular}{lcccc}
\hline Rank & Dimensions & Mean & Standard deviation & $\begin{array}{c}\text { Level in relation to } \\
\text { the mean }\end{array}$ \\
\hline 1 & Objectivity & 4.30 & 0.59 & High \\
\hline 3 & $\begin{array}{c}\text { Administrative } \\
\text { Communications }\end{array}$ & 4.19 & 0.81 & High \\
\hline 2 & Effectiveness & 4.26 & 0.73 & High \\
\hline- & Total & 4.25 & 0.59 & High \\
\hline
\end{tabular}

Table No. (5) Shows that the means of the perceptions of the individuals of the study sample came with a high degree, with a mean (4.25), and a standard deviation (0.59). This is followed by the effectiveness dimension, with a mean of (4.26), the third and final dimension of administrative communications, with an average of (4.19); the following is a detailed presentation of the level of each of these dimensions:

The first dimension: objectivity

Table 6. Means and standard deviations of the study sample individual's perceptions of the objectivity dimension

\begin{tabular}{llcccc}
\hline No. & Rank & Items & Mean & $\begin{array}{c}\text { Standard } \\
\text { deviation }\end{array}$ & $\begin{array}{c}\text { Level in relation to the } \\
\text { mean }\end{array}$ \\
\hline 1 & 1 & The commander's words are consistent with & 4.35 & 0.74 & High \\
his actions. & High & & \\
\hline 2 & 5 & $\begin{array}{c}\text { The leader listens attentively to every } \\
\text { conversation directed at him. }\end{array}$ & 4.12 & 0.69 & High \\
\hline 3 & 2 & The leader raises challenge and fortitude in us. & 4.28 & 0.71 & High \\
\hline 4 & 4 & $\begin{array}{c}\text { The leader reinforces the desired changes in a } \\
\text { logical manner. }\end{array}$ & 4.19 & 0.79 & High \\
\hline 5 & 3 & $\begin{array}{c}\text { The leader courageously tackles the } \\
\text { difficulties of business development. }\end{array}$ & 4.21 & 0.91 & High \\
\hline
\end{tabular}

It appears from Table No. (6) that the general average of perceptions of the vocabulary of the study sample for the objectivity dimension was of a high degree, with a mean of (4.23) and a standard deviation (0.59). Item No. (1) "The leader's words are consistent with his actions" ranked first, with a mean of (4.35) and a high degree of consistentency, while item No. (2) "The Leader listens with interest for every speak directed to him" came last among the item of this dimension, and with a mean of (4.12), which reflects a high degree of consistentency.

The second dimension: administrative communications

Table 7. Means and standard deviations of the study sample individual perceptions of the administrative communication dimension

\begin{tabular}{lccccc}
\hline No. & Rank & Item & Mean & $\begin{array}{c}\text { Standard } \\
\text { Deviation }\end{array}$ & $\begin{array}{c}\text { Level in } \\
\text { relation to } \\
\text { the mean }\end{array}$ \\
\hline 6 & 2 & $\begin{array}{c}\text { Encouraging the university's administrative and academic } \\
\text { leaderships to communicate from the bottom up. }\end{array}$ & 4.25 & 0.74 & High \\
\hline 7 & 5 & $\begin{array}{c}\text { Organizing periodic meetings between administrative, academic } \\
\text { and lower-level leaderships to explain and discuss some } \\
\text { instructions. }\end{array}$ & 4.02 & 0.69 & High \\
\hline 8 & 1 & $\begin{array}{c}\text { The university has means of expressing opinion and dialogue, } \\
\text { such as the Complaints and Suggestions Box. }\end{array}$ & 4.40 & 0.71 & High \\
\hline 9 & 4 & $\begin{array}{c}\text { The administrative and academic leaderships of the university } \\
\text { encourage individuals to express their proposals. }\end{array}$ & 4.12 & 0.79 & High \\
\hline 10 & 3 & $\begin{array}{c}\text { The university's administrative communication systems provide } \\
\text { information to employees as quickly and in a timely manner as } \\
\text { possible }\end{array}$ & 4.16 & 0.91 & High \\
\hline Administrative Communications & 4.19 & & 0.80 \\
\hline
\end{tabular}

Table No. (7) shows that the general average of perceptions of the individuals of the study sample for the 
dimension of administrative communications came with a high degree, with a mean of (4.19), and a standard deviation (0.80), item No. (8) "In the university there are means to express your opinion such as Complaints and a Suggestions Box "ranked first, with a mean of (4.40), with a high degree of consistency, while item no. (7)" organizes periodic meetings between administrative and academic leaders and lower levels to explain and discuss some instructions ranked last among the items of this dimension, with a mean of (4.02), which reflects a high degree of consistency.

The third dimension: effectiveness

Table 8. Means and standard deviations of the study sample individual's perceptions of the effectiveness dimension

\begin{tabular}{lccccc}
\hline No. & Rank & Items & Mean & $\begin{array}{c}\text { Standard } \\
\text { deviation }\end{array}$ & $\begin{array}{c}\text { Level in relation to } \\
\text { the mean }\end{array}$ \\
\hline 11 & 1 & $\begin{array}{c}\text { Administrative and academic leaderships develop } \\
\text { alternative plans to face the fluctuations of their } \\
\text { environment. }\end{array}$ & 4.60 & 0.70 & High \\
\hline 12 & 3 & $\begin{array}{c}\text { Encouraging administrative and academic leaders, } \\
\text { work programs aimed at integrating into society. }\end{array}$ & 4.21 & 0.79 & High \\
\hline 13 & 2 & $\begin{array}{c}\text { The university invests all its financial, human and } \\
\text { technical resources to achieve its goals. }\end{array}$ & 4.28 & 0.78 & High \\
\hline 14 & 5 & The university provides an accurate description of the \\
tasks of each position. & 4.10 & 0.80 & High \\
\hline 15 & 4 & The administrative and academic leaderships \\
appreciate my efforts at work. & 4.15 & 0.90 & High \\
\hline objectivity & & 4.27 & 0.75 & High \\
\hline
\end{tabular}

It appears from Table No. (8) That the general average of perceptions of the individuals of the study sample for the effectiveness dimension was high, with a mean of (4.27) and a standard deviation (0.75). Item No. (11)" the administrative and academic leaderships alternative plans to face the fluctuations of their environment" occupied First place, with a mean of (4.60) and a high degree of consistency, while item No. (14) "The university provides an accurate description of the tasks of each job" came in the last place among the items of this dimension, with a mean of (4.10), which reflects a high degree of consistency.

\subsection{Answer the Second Question}

Identify the respondents' perceptions towards achieving governance, with each of its dimensions (justice, equality, accountability) in the official Jordanian universities in southern Jordan. To answer this question; the mean and standard deviations were calculated for the perceptions of the individuals of the study sample, at the level of each dimension, and the overall dimension to achieve governance, and Table (9) illustrates the results of this:

Table 9. Means and standard deviations of the perceptions of the study sample individuals towards achieving governance

\begin{tabular}{lcccc}
\hline Rank & Dimensions & Mean & Standard deviation & Level in relation to the mean \\
\hline 2 & Justice and equality & 4.40 & 0.77 & High \\
\hline 1 & Accountability & 4.45 & 0.65 & High \\
\hline- & Total & 4.35 & 0.67 & High \\
\hline
\end{tabular}

Table No. (9) Shows that the means of perceptions of the individuals of the study sample as a whole came with a high degree, with a mean of (4.35) and a standard deviation of (0.67). Perceptions at dimensional level came at a high degree, where accountability dimension ranked first, with a mean of (4.45), followed by the dimension of justice and equality, with a mean of (4.40), and the following is a detailed presentation of the level of each of these dimensions:

The first dimension: justice and equality 
Table 10. Means and standard deviations of the study sample's individual are perceptions of the justice and equality dimension

\begin{tabular}{lccccc}
\hline No & Rank & Items & Mean & $\begin{array}{c}\text { Standard } \\
\text { deviation }\end{array}$ & $\begin{array}{c}\text { Level in } \\
\text { relation to the } \\
\text { mean }\end{array}$ \\
\hline 16 & 4 & $\begin{array}{c}\text { The university forms committees to work on creating } \\
\text { a balance between the university budget and the } \\
\text { optimal investment of resources. }\end{array}$ & 4.32 & 0.86 & High \\
\hline 17 & 3 & $\begin{array}{c}\text { The university adopts members 'proposals at } \\
\text { procedural levels. }\end{array}$ & 4.33 & 0.75 & High \\
\hline 18 & 2 & Academic and administrative staff has clear criteria \\
for receiving promotions. & 4.37 & 0.77 & High \\
\hline 19 & 1 & The criteria for performance evaluation are fair and \\
objective. & 4.39 & 0.79 & High \\
\hline & & Justice And Equality Dimension & 4.32 & 0.86 & High \\
\hline
\end{tabular}

Table No. (10) Shows that the general average of perceptions of the study sample's individuals of the dimension of justice and equality came with a high degree, with a mean of (4.35), and a standard deviation of (0.68). Item No. (19) "The criteria for performance evaluation are fair and objective" ranked first, with a mean of (4.39) with a high degree of consistency, while item No. (16) "The University forms committees specialized in creating a balance between the university's budget and the optimal investment of resources" in the last place among the items of this dimension, with an average of (4.32), which reflects a high degree of consistency.

The second dimension: accountability:

Table 11. Means and standard deviations of the study sample individual's perceptions of the accountability dimension

\begin{tabular}{|c|c|c|c|c|c|}
\hline No & Rank & Items & Mean & $\begin{array}{l}\text { Standard } \\
\text { deviation }\end{array}$ & $\begin{array}{l}\text { Level in relation to } \\
\text { the mean }\end{array}$ \\
\hline 20 & 1 & $\begin{array}{l}\text { The university applies accountability to } \\
\text { achieve quality. }\end{array}$ & 4.48 & 0.74 & High \\
\hline 21 & 2 & $\begin{array}{l}\text { The university grants independence to the } \\
\text { internal reference committees. }\end{array}$ & 4.39 & 0.83 & High \\
\hline 22 & 3 & $\begin{array}{l}\text { The university exercises accountability } \\
\text { without discrimination between occupational } \\
\text { statuses when deviations in performance } \\
\text { occur. }\end{array}$ & 4.33 & 0.81 & High \\
\hline 23 & 4 & $\begin{array}{l}\text { The university provides a special department } \\
\text { for continuous performance monitoring. }\end{array}$ & 4.27 & 0.81 & High \\
\hline 24 & 5 & $\begin{array}{l}\text { The university announces its policy of } \\
\text { internal control. }\end{array}$ & 4.20 & 0.87 & High \\
\hline \multicolumn{3}{|c|}{ Accountability } & 4.33 & 0.76 & High \\
\hline
\end{tabular}

Table No. (11) Shows that the general average of the perceptions of the study sample for the accountability dimension was high, with a mean of (4.33) and a standard deviation of (0.76). Item No. (20) "The University applies accountability to achieve quality" ranked first, with a mean of (4.57) and a high degree of consistency, while item No. (24) "The University announces its policy of internal control" came last among the items of this dimension, with a mean of (4.20), which reflects a high degree of consistency.

\subsection{Test Hypotheses of the Study}

Results of the main hypothesis test: There is no statistically significant impact at the level of significance $\quad(\alpha \leq$ 0.05 ) for administrative and academic leadership trends in its dimensions (objective, administrative communication, effectiveness) on achieving governance in its dimensions (justice, equality, accountability) in the official Jordanian universities in southern Jordan. 
Table 12. Results of multiple regression analysis to test the impact of leadership trends in their various dimensions on governance

\begin{tabular}{lccccc}
\hline $\begin{array}{l}\text { Dimensions of the } \\
\text { concept of leadership } \\
\text { trends }\end{array}$ & B & Standard error & Beta & (t) value & $\begin{array}{c}\text { Statistical } \\
\text { significance }\end{array}$ \\
\hline Objectivity & $0.075-$ & 0.062 & 0.095 & $1.046-$ & 0.275 \\
\hline $\begin{array}{l}\text { Administrative } \\
\text { Communications }\end{array}$ & 0.171 & 0.081 & 0.192 & $3.210^{*}$ & 0.019 \\
\hline Effectiveness & 0.102 & 0.055 & 0.157 & 1.390 & 0.113 \\
\hline
\end{tabular}

*Statistically significant at $(\alpha \leq 0.05)$ significance level

It is evident from the statistical results in Table (12) and from the follow-up of (Beta) values, and the (t) test. The dimension of the independent variable (administrative communication) has a statistically significant impact on the dependent variable (governance) in terms of the height of the (t) calculated values shown in in Table (12) at the level of Significance of $(\alpha \leq 0.05)$ and the statistically significant impact force of (Beta) values. The results also indicated in the above table that there is no statistically significant impact of the dimensions of the independent variable (objectivity and effectiveness) on the dependent variable (governance) in terms of a decrease in the calculated $(\mathrm{t})$ values appearing in in Table (12) and a high level of significance than $(\alpha \leq 0.05)$ and the statistically significant influential force of Beta values.

Table 13. Results of a Step Wise Multiple Regression analysis to predict governance through the dimensions of leadership trends

\begin{tabular}{llll}
\hline $\begin{array}{l}\text { The order of entry of the independent variables into the } \\
\text { prediction equation }\end{array}$ & $\mathrm{R}^{2}$ & $\mathrm{t}$ ) value & Significant value $\mathrm{t}$ \\
\hline Objectivity & 0.304 & $6.238^{*}$ & 0.000 \\
\hline Administrative Communications & 0.489 & $4.260^{*}$ & 0.001 \\
\hline Effectiveness & 0.531 & $4.110^{*}$ & 0.002 \\
\hline
\end{tabular}

*Statistically significant at $(\alpha \leq 0.05)$ significance level

When performing a step-wise multiple regression analysis to determine the importance of each dimension of the independent factor separately in contributing to the mathematical model $y=a+b x$, which represents the impact of the dimensions of leadership trends in governance, the previous table shows the order of entry of the dimensions of the independent factor into the regression equation. The subjectivity dimension ranked first and explained an amount (30.4\%) of the variance in the dependent variable (governance), followed by the administrative communications that explained with the subjectivity dimension (48.9\%) of the variance in the dependent variable (governance).Finally the effectiveness dimension explains with the previous two dimensions an amount $(53.1 \%)$ of the variance in the dependent variable governance.

Results of the first sub-hypothesis test: There is no statistically significant impact at the level of significance ( $\alpha \leq$ 0.05) of the administrative and academic leadership trends in their dimensions (objective, administrative communication, effectiveness) on justice and equality as one of the dimensions of achieving governance in the official Jordanian universities in southern Jordan.

Table 14. Results of multiple regression analysis to test the impact of leadership trends in their various dimensions on justice and equality as one of the dimensions of governance.

\begin{tabular}{lccccc}
\hline $\begin{array}{l}\text { Dimensions of the concept of } \\
\text { leadership trends }\end{array}$ & $\mathrm{B}$ & Standard error & Beta & (t) value & $\begin{array}{c}\text { Statistical } \\
\text { significance }\end{array}$ \\
\hline Objectivity & $0.118-$ & 0.078 & $0.111-$ & $1.602-$ & 0.174 \\
\hline Administrative Communications & 0.173 & 0.082 & 0.162 & 1.279 & 0.161 \\
\hline Effectiveness & 0.193 & 0.061 & 0.273 & $2.820^{*}$ & 0.002 \\
\hline
\end{tabular}

*Statistically significant $(\alpha \leq 0.05)$ significance level

It is evident from the statistical results mentioned in the previous table, and from the follow-up of (Beta) coefficients, and the test of (objectivity, the independent variable (effectiveness), respectively, that have a statistically significant impact on the dependent variable (fairness and equality) in terms of the high value of the 
calculated $(t)$, shown in the previous table at the level of significance $(\alpha \leq 0.05)$ and the influential statistically significant force of (Beta) values. The results in the above table also indicated that there is no statistically significant impact of the dimensions of the independent variable (objectivity, administrative communication) on the dependent variable (justice and equality) in terms of a decrease in ( $t$ ) calculated values shown in the previous table at the level of significance $(\alpha \leq 0.05)$ and the statistically significant influence force of (Beta) values.

Table 15. Results of Step Wise Multiple Regression analyze to predict justice and equality through the dimensions of leadership trends

\begin{tabular}{|c|c|c|c|}
\hline $\begin{array}{l}\text { The order of entry of the } \\
\text { independent variables into the } \\
\text { prediction equation }\end{array}$ & $\mathrm{R}^{2}$ & Calculated $(\mathrm{t})$ value & The significance level of( $t)$ \\
\hline Objectivity & 0.451 & *5.325 & 0.000 \\
\hline Administrative Communications & 0.631 & $2.117 *$ & 0.001 \\
\hline
\end{tabular}

*Statistically significant at $(\alpha \leq 0.05)$ level.

When performing a Step Wise Multiple Regression analysis to determine the importance of each dimension of the independent factor separately in contributing to the mathematical model that represents the impact of the dimensions of leadership trends in justice and equality, the previous table shows the order of entry of the dimensions of the independent factor into the regression equation. Objectivity dimension ranked first, and explained an amount (45.1\%) of the variance in the dependent variable (justice and equality), followed by administrative communications that explained with the objectivity dimension an amount $(63.1 \%)$ of the variance in the dependent variable (justice and equality), which came out of equation.

Results of the second sub-hypothesis test: There is no statistically significant impact at the level of significance $(\alpha \leq 0.05)$ for administrative and academic leadership trends in their dimensions (objective, administrative communication, and effectiveness) in the aspect of accountability from the dimensions of achieving governance in the official Jordanian universities in southern Jordan.

Table 16. Results of multiple regression analysis to test the impact of leadership trends with their different dimensions on accountability as one of the dimensions of governance

\begin{tabular}{lccccc}
\hline $\begin{array}{l}\text { Dimensions of the concept of } \\
\text { leadership trends }\end{array}$ & $\mathrm{B}$ & Standard error & Beta & (t) value & $\begin{array}{c}\text { Statistical } \\
\text { significance }\end{array}$ \\
\hline Objectivity & $0.118-$ & 0.070 & $0.152-$ & $1.221-$ & 0.131 \\
\hline $\begin{array}{l}\text { Administrative } \\
\text { Communications }\end{array}$ & 0.181 & 0.061 & 0.308 & 3.402 & 0.025 \\
\hline \multicolumn{1}{c}{ Effectiveness } & 0.132 & 0.054 & 0.185 & 3.610 & 0.019 \\
\hline
\end{tabular}

*Statistically significant at $(\alpha \leq 0.05)$ significance level

It is evident from the statistical results shown in the previous table and from the follow-up of (Beta) coefficients and (t) test that the dimensions of the independent variable (administrative communication and effectiveness), respectively, have a statistically significant impact on the dependent variable (accountability) in terms of the high calculated $(t)$ values shown in the previous table at the level of significance $(\alpha \leq 0.05)$ and the statistically significant influence force of (Beta) values. The results also indicated in the above table that there is no statistically significant impact of the dimension of the independent variable (objectivity) in the dependent variable (governance) in terms of the decrease of the $(t)$ calculated values shown in the previous table at the level of significance $(\alpha \leq 0.05)$ and the statistically significant influential force of (Beta) values .

Table 17. Results of Step Wise Multiple Regression analyzes to predict accountability through the dimensions of leadership trends

\begin{tabular}{lllc}
\hline Dimensions of the concept of leadership trends & B & (t) value & $\begin{array}{c}\text { Statistical } \\
\text { significance }\end{array}$ \\
\hline Objectivity & 0.326 & $5.400^{*}$ & 0.000 \\
\hline Administrative Communications & 0.377 & $3.136^{*}$ & 0.003 \\
\hline Effectiveness & 0.418 & $3.590^{*}$ & 0.028 \\
\hline
\end{tabular}

*Statistically significant at $(\alpha \leq 0.05)$ significance level 
When performing a step-wise multiple regression analysis to determine the importance of each dimension of the independent factor separately in contributing to the mathematical model that represents the impact of the dimensions of leadership trends in accountability, the previous table shows the order of entry of the dimensions of the independent factor into the regression equation objectivity ranked first and explained an amount of (32.6\%) of the variance in the dependent variable (accountability), followed by the administrative communication dimension, which explained with the objectivity dimension an amount (37.7\%) of the variance in the dependent variable (accountability). Finally, the activity dimension was entered which explained with the previous two dimensions, an amount of (41.8\%) of the variance in the dependent variable (accountability).

\section{Discussing the Results}

Discuss the findings of the study

1. The results showed that the means of the respondents' perceptions of leadership trends in the official Jordanian universities in southern Jordan were of a high degree, and the perceptions at the level of dimensions also came in a high degree.

2. The results showed that the means of the respondents' perceptions of governance in the official Jordanian universities in southern Jordan came with a high degree, and the perceptions of the dimensions came in a high degree.

3. The results showed that there is a statistically significant impact at the level of significance $(\alpha \leq 0.05)$ for leadership trends in their dimensions (objectivity, administrative communication, and effectiveness) combined on governance. Separately, it was found that the dimension of the independent variable (administrative communication) has a statistically significant impact on the dependent variable (governance), while it was found that there is no statistically significant impact of the dimensions of the independent variable each one separately (objectivity and effectiveness) on the dependent variable governance.

4. The results indicated that there is a statistically significant impact at the level of significance $(\alpha \leq 0.05)$, of leadership trends in all dimensions (objectivity, administrative communication, effectiveness) on justice and equality as a dimension of governance. The results showed that the dimension of the independent variable (effectiveness), respectively, has a statistically significant impact on the dependent variable (justice and equality), while there is no statistically significant impact of the dimensions of the independent variable separately (objectivity, administrative communications) on the dependent variable (justice and equality)

5. The results also indicated that there is a statistically significant impact at the level of significance $(\alpha \leq 0.05)$ of leadership trends in their combined dimensions (objectivity, management communication, effectiveness) on accountability as a dimension of governance.

\section{Recommendations}

1. Paying attention to the continuous training of leaders on understanding administrative activity, especially in the field of leadership behavior in universities, to activate the role of leaders in these universities.

2. That the leader relies on effective communication by listening well to his employees and allowing them to express themselves.

3. Paying attention to the necessity of conducting more comparative studies on the attitudes of senior leaders in the official Jordanian universities in southern Jordan towards governance and ways to develop it in all Jordanian public universities.

4. Spreading and strengthening the culture of governance among employees, because this will be reflected on the decisions of the institution, as well as positively on its performance.

5. Establishing a system of governance announced to all parties concerned with its implementation, clarifying the duties and responsibilities of each employee in the institution.

6. Starting the actual application of the principles of governance to reduce administrative corruption and improve performance in Jordanian public universities.

\section{References}

Adelopo, I. (2010). The Impact of Corporate Governance on Auditor Independence: A Study of Audit Committees in UK Listed Companies. PhD Thesis, Faculty of Business and Law. De Montfort University, UK.

Al Hrout, A. I. (2018). Attitudes Towards the Implementation of Electronic Governance in Jordanian Private Universities and their Impact on the Excellence of Universities Performance: Field Study. unpublished 
master's thesis, Faculty of Business, Middle East University, Jordan.

Al-Abdali, M. A. H. (2012). The Effect of Corporate Governance Implementation Upon the Quality of Internal Audit on the Industrial Companies Listed at Kuwait Stock Exchange. unpublished master's thesis, Faculty of Business, Middle East University, Jordan.

Al-Ajami, M. (2008). Modern Trends in Administrative Leadership and Human Development. Dar Al-Masirah for Publishing, Distribution and Printing, Jordan.

AL-Arini, M. B., \& Abdulaziz, B. A. (2014). The Reality of the Implementation of Governance from the Viewpoint of Members of the Administrative and Academic Bodies Working at the Imam Muhammad bin Saud Islamic University. Specialized International Educational Journal, Jordan, 12(3).

Al-Jabali, S., \& Al-Mahamid, A. (2018). The Impact of University Governance on Employee Satisfaction and Retention: A Field Study in Jordanian Private Universities. Journal of the Association of Arab Universities for Research in Higher Education, 38(2).

Al-Khathami, M. S. S. (2020). Creative leadership practice with school leaders in Khamis Mushait governorate from the point of view of teachers. Journal of Faculty of Education Assiut, University, 36(1), 483-508, Retrieved from https://digitalcommons.aaru.edu.jo/jfe_au/vol36/iss1/2

Al-Rashidi, A. D. (2018).Transformational Leadership and its Relationship to Organizational Creativity among Deans and Heads of Departments at Governmental and Private Universities in Riyadh, The Arab Journal of Security Studies. Naif Arab University for Security Sciences, 33(71).

Al-Saadi, A. M. R. (2021). The Impact of Creative Leadership on Organizational Effectiveness: Strategic Thinking as a Variable Mediator, Case Study - Dubai Police. unpublished master's thesis, College of Business, Mutah University, Jordan.

Al-Senussi, I. W. (2016). The Impact of Governance on Achieving Competitive Advantage, a Field Study in Private Hospitals in Amman. Unpublished Master Thesis, College of Business, Middle East University, Amman.

Ayasrah, M. M. (2008). Leadership, Control and Administrative Communication, Al-Hamed Publishing and Distribution House, Amman, Jordan (1st ed.).

By, R. T. (2021). Leadership: In pursuit of purpose. Journal of Change Management, 21(1), 30-44, https://doi.org/10.1080/14697017.2021.1861698

Christensen, M. P. S. (2007). Framing and Overflowing of Public Sector Accountability Innovations: A Comparative Study of Reporting Practices. Accounting، Auditing \& Accountability Journal, 2. https://doi.org/10.1108/09513570710731227

Hill, C. W., \& Jones, G. R. (2016). Strategic Management Theory: An Integrated Approach. Houghton Mifflin, Co.

Kafi, M. Y. (2013). The economic and global financial crisis and corporate governance (its roots - its causes its repercussions - its horizons) (1st ed.). Arab Society Library for Publishing and Distribution, Amman, Jordan.

Kanaan, N. (2009). Administrative Leadership. House of Culture for Publishing and Distribution, Jordan.

Magee II, P. R. (2018). Strategic Leadership Primer, Development of Command, Leadership \&Management. U.S. Army War College.

Maher, M. H. (2014). Leadership, Basics, Theories and Concepts. Al-Kindi House for Publishing and Distribution, Amman, Jordan.

Moufiedah, G. (2018). Administrative Leadership and its Role in Supporting Administrative Creativity at the Central Library of Al-Arabi Bin Mahidi University - Umm Al-Bouaghi. an unpublished MA.

Nouri, B. M., \& Salman, A. K. (2010). Corporate Governance and its Role in Reducing Agency Theory Problems. International Forum on Creativity and Organizational Change in Modern Organizations, Al-Mustansiriya University, Iraq.

Nwachukwu, C. H. V. (2020). Creative Leadership and Creativity: An Overview. Granada. Spain.

Schnurr, S., \& Schroeder, A. (2019). A critical reflection of current trends in discourse analytical research on leadership across disciplines. A call for a more engaging dialogue. Leadership, 15(4), 445-460. https://doi.org/10.1177/1742715018767687 
Williamson, Q. E. (1999). The Mechanism of Governance. Oxford University Press.

Yuliastuti, I. A. N., \& Tandio, D. R. (2020). Leadership Style on Organizational Culture and Good Corporate Governance. International Journal of Applied Business and International Management, 5(1), 23-33, https://doi.org/10.32535/ijabim.v5i1.764

\section{Copyrights}

Copyright for this article is retained by the author(s), with first publication rights granted to the journal.

This is an open-access article distributed under the terms and conditions of the Creative Commons Attribution license (http://creativecommons.org/licenses/by/4.0/). 